ISSN (O) 2589-8779

(P) 2589-8760

CMRO 04 (03), 878-885 (2021)

ORIGINAL ARTICLE

\title{
Peripheral Nerve Blockade and Botox Treatment in Chronic Migraine: A Comparative Study
}

\section{Adnan Burak Bilgic ${ }^{1^{*}} \mid$ Cetin Kürsad Akpinar $^{1} \mid$ Ulku Turk Boru² ${ }^{2}$ Leyla Ramazanoglu ${ }^{3}$}

${ }^{1}$ Health Sciences University

Samsun Education and Research Hospital

${ }^{2}$ Afyonkarahisar Health Sciences University Hospital

${ }^{3}$ Health Sciences University Fatih Sultan Mehmet Training and Research Hospital

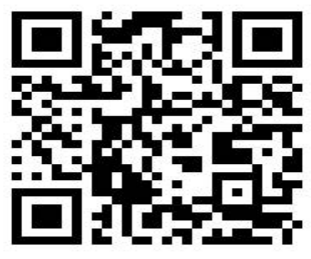

\section{1 | INTRODUCTION}

$\mathrm{M}$ igraine is the most commonly encountered disabling headache. Chronic migraine significantly affects the quality of life and ICHD-3

\begin{abstract}
Migraine is the most commonly encountered disabling headache. Chronic migraine significantly affects the quality of life and reduces the ability to attend work and social events, and consequently becomes an increasing economic burden.In recent years, peripheral nerve block with botulinum toxin A (botox) and local analgesics has been included in alternative treatment regimens. In cases of chronic migraine, botox is injected into the facial area, maxillary and mandibular nerve, and the head and neck muscles.Recent methods such as great occipital nerve (GON), and lesser occipital nerve, supra orbital nerve (SON), sphenopalatine ganglion blockade and trigeminal ganglion blockade have been applied using local analgesics. GON and SON blockade are the most frequently used of these methods. Studies related to these methods have shown a decrease in the frequency and severity of migraine pain. The results of this study showed that both GON and SON blockade and long-term application of BTX-A treatment were highly effective in the treatment of chronic migraine and both treatment methods had a similar level of effectiveness. That the follow-up period of this study was longer than in previous research can be considered a strong aspect of the study.
\end{abstract}

Keywords: BTX-A, migraine, great occipital nerve, supra orbital nerve,

Copyright : (C) 2021 The Authors. Published by Publisher. This is an open access article under the CC BY-NC-ND license (https://creativecommons.org/licenses/by-nc-nd/4.0/). reduces the ability to attend work and social events, and consequently becomes an increasing economic burden (1-3).

Although many methods have been attempted in the treatment of chronic migraine, the outcomes have not 


\section{CURRENT MEDICAL RESEARCH AND OPINION}

been fully satisfactory. Painkillers and anti-migrane medication are standard treatment modalities during acute attacks, but the drugs used in the treatment of acute attacks do not provide long-term effectiveness. Moreover, the long-term use of painkillers causes various side-effects and new types of headaches.

Anti-epileptics, calcium antagonists, beta-blockers and antidepressants are among the most commonly used drugs in migraine prophylaxis. In addition, complementary medicine and behavioral management techniques are resorted to as alternatives (4).

In recent years, peripheral nerve block with botulinum toxin A (botox) and local analgesics has been included in alternative treatment regimens.

In cases of chronic migraine, botox is injected into the facial area, maxillary and mandibular nerve, and the head and neck muscles.

Recent methods such as great occipital nerve (GON), and lesser occipital nerve, supra orbital nerve (SON), sphenopalatine ganglion blockade and trigeminal ganglion blockade have been applied using local analgesics. GON and SON blockade are the most frequently used of these methods. Studies related to these methods have shown a decrease in the frequency and severity of migraine pain $(5,6)$.

The use of both GON and botox applications in resistant migraine cases has gradually increased due to effective positive results. However, there has been no study comparing the effect of peripheral nerve blockade and botox application in chronic migraine.

The aim of this study was to compare the effect of supraorbital and greater occipital nerve blockade and botox treatment on chronic migraine.

Supplementary information The online version of this article (https://doi.org/10.15520/jcmro.v4i03.41 0 ) contains supplementary material, which is available to authorized users.

Corresponding Author: Adnan Burak Bilgic

Health Sciences University Samsun Education and Research Hospital

Email: bilgicadnan0@gmail.com

\section{2 | MATERIAL AND METHOD}

This retrospective study included 42 patients diagnosed with chronic migraine according to The International Classification of Headache Disorders, 3 rd edition (beta version) (ICHD-3). A retrospective review was made of the records of patients that underwent GON, SON blockade and botilinum toxin A injection between 1 January 2018 and 1 December 2018. The patients included in the study were aged $\geq 18$ years, had been diagnosed with chronic migraine and elected to receive at least $1 \mathrm{GON}, \mathrm{SON}$ or botolinum toxin A injection. Patients who received nerve blocks not specific to the injection regions were excluded from the study.

A record was made for each patient of age, height, weight, body mass index, sex, history of migraine, family history of migraine, home medications, utilization of a migraine diary, presence of aura, frequency and severity of migraines, visits to the emergency department, and interference with daily productivity. Patient's home medications for treatment and prophylaxis of migraines were assessed and categorized as either current therapy or failed therapy. Current therapy was defined as medications that were still providing some relief, whereas failed therapy was accepted as medications that no longer provide migraine relief.

\section{Botox Procedure:}

A total of 20 patients were included in the botolinum toxin injection group.

According to the PREEMPT (Phase 3 Research Evaluating Migraine Prophylaxis Therapy) protocol, the patients were administered a fixed dose and injection of 155 iu on admission to the same areas and botulinum toxin at 6th and 12th months (literature). Before the procedure, pain level (VAS) and attack frequency were noted. At least a 50\% decrease in VAS and frequency in a 3-month period was defined as a positive response. Treatment termination criteria were defined as side-effects, ineffectiveness, or inadequate effectiveness. Patients with these symptoms were recorded. 


\section{Lidocaine Procedure:}

The GON and SON groups included 22 patients. The injection of $2 \%$ lidocaine and $0.9 \% 1 \mathrm{ml}$ saline was mixed and injected into the bilateral supraorbital and greater occipital nerves. Each GON was injected $0.75 \mathrm{ml}$, and SON $0.25 \mathrm{ml}$. Patients were blinded to the injection type. Double blinding could not be fully achieved for technical reasons (lack of separate rooms and separate persons in the study area).

The GON injection site was determined as $2 \mathrm{~cm}$ lateral and $2 \mathrm{~cm}$ inferior to the external occipital protuberance. The SON injection site was adjacent to the supraorbital incisura on the frontal bone. The injection was applied based on the frontal and occipital bone. Touching the periostium, the needle was pulled back slightly, and then the solution was injected. Local pressure was applied for 2-3 minutes to spread the solution and prevent bleeding. These injections were administered once a week for 4 weeks, and monthly thereafter. When the treatment was completed, the patients were followed up in the outpatient clinic for 12 months to evaluate the clinical response. Each patient kept a headache diary, recording the number of headache days per month and pain intensity. Pain frequency and VAS pain scores recorded 1 month before treatment and at 0,6 and 12 months during the treatment were compared with post-treatment values in both groups.

\section{Ethical approval:}

Ethics Committee approval was obtained for this study with the decision number 07.11.2019 / 06 . Informed consent was obtained from the patients for the procedure.

\section{Statistical analysis:}

Statistical analyses of the study data were performed using SPSS version 17.0 for Windows software.

Using OpenEpi version 3.01 software, the sample size was calculated as a minimum of 37 patients in each group. Continuous data were stated as mean, standard deviation, median, and range values and categorical data as number and percentage. Chisquare and Mauchly's Test of Sphericity tests were used to compare demographic data and for the between-group comparisons. A value of $p<0.05$ was considered statistically significant.

\section{3 | RESULTS}

A total of 42 patients were included. 3 patients dropped out of the study due to ineffectiveness of GON and SON blockade, and 2 patients from the botox group due to a change of address. No patient left the treatment during the course of the treatment.

\section{Bilateral SON and GON Blockade Group:}

The patients applied with GON and SON comprised $14(68.4 \%)$ females and $5(31.6 \%)$ males with a mean age of $32.78 \pm 7.72$ years. The mean disease duration was $9.63 \pm 3.68$ years, and the mean number of attacks before the procedure was $11.00 \pm 2.62$ per month and the mean VAS was $7.31 \pm 0.94$ Table 1

The mean VAS score of the patients after the treatment was $6.36 \pm 1.01$ in the first month, $6.10 \pm 1.14$ in the 6 th month, and $4.31 \pm 1.49$ in the 12 th month. The number of attacks after the procedure was $4.73 \pm$ 2.20 in the 1 st month, $4.10 \pm 2.05$ in the 6 th month, and $6.10 \pm 1.19$ at the end of the 1 st year Table 2 .

The mean frequency of attacks was measured as 6.21 \pm 2.80 in the 1 st month after the treatment, $5.89 \pm$ 2.60 in the 6 th month and $5.63 \pm 2.58$ in the 12 th month Table 3.

\section{Botox A injection group:}

The patients who received botolinum toxin injection comprised14 females (77.8\%) and 4 males $(22.2 \%)$ with a mean age of $35.88 \pm 7.02$ years. Mean disease duration was $10.22 \pm 4.73$ years. Before the procedure, the mean monthly VAS score was $7.61 \pm 1.09$ and the number of attacks was $11.72 \pm 2.58$ Table 1 .

During the treatment, the mean VAS scores of the patients were $5.66 \pm 1.53$ in the first month, 5.27 \pm 1.74 in the $6^{\text {th }}$ month, and $4.94 \pm 1.86$ in the $12^{\text {th }}$ month Table 2 . The number of attacks after the procedure was $5.83 \pm 2.12$ in the 1 st month, $4.22 \pm$ 1.43 in the 6 th month, and $3.38 \pm 1.78$ at the end of the 1st year Table 3 .

No statistically significant difference was found between the GON, SON and Botox groups in respect of age, gender, or family histories Table 1 .

Vasovagal syncope and minimal hemorrhage were present in 2 patients in the GON, SON group, and local pain and moderate muscle atrophy in the temporal region developed after 6 months in 2 patients 
TABLE 1: Demographicdata

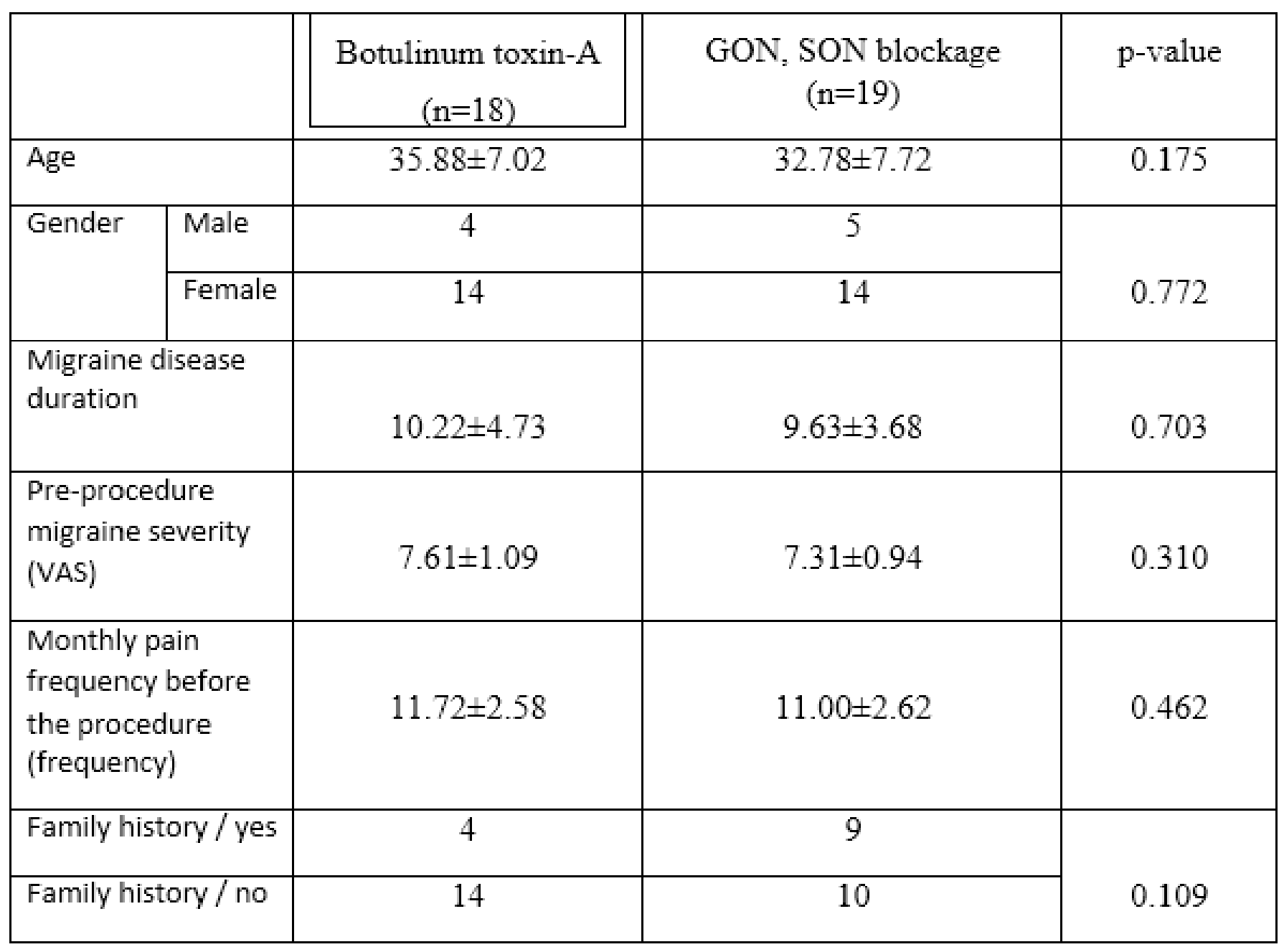

TABLE 2: Comparisonof VAS between groups, t0: before the procedure, $\mathrm{t} 1 \mathrm{:}$ : 1st month after theprocedure, $\mathrm{t} 6:$ th month after the procedure, $\mathrm{t} 12: 12$ th month after theprocedure

\begin{tabular}{|l|l|c|c|}
\hline Time & Group & Mean \pm sd) & P-value \\
\hline T0 & Botilinum toxin A & $7.61 \pm 1.09$ & \multirow{2}{*}{0.310} \\
\cline { 2 - 3 } & GON,SON blokaj & $7.31 \pm 0.94$ & \\
\hline T1 & Botilinum toxin A & $5.66 \pm 1.53$ & \multirow{2}{*}{0.134} \\
\cline { 2 - 3 } & GON,SON blokaj & $6.36 \pm 1.01$ & \multirow{2}{*}{0.132} \\
\hline \multirow{2}{*}{ T6 } & Botilinum toxin A & $5.27 \pm 1.74$ & \multirow{2}{*}{0.043} \\
\cline { 2 - 3 } & GON,SON blokaj & $6.10 \pm 1.14$ & \\
\hline \multirow{2}{*}{ T12 } & Botilinum toxin A & $4.94 \pm 1.86$ & \\
\cline { 2 - 3 } & GON,SON blokaj & $6.10 \pm 1.19$ & \\
\hline
\end{tabular}


TABLE 3: Comparisonof pain frequency (frequency) between groups, t0: before the procedure, $\mathrm{t} 1$ : 1stmonth after the procedure, $\mathrm{t} 6:$ th month after the procedure, t12: 12th monthafter the procedureT

\begin{tabular}{|l|l|l|l|}
\hline Time & Group & Mean \pm sd) & P-value \\
\hline T0 & Botilinum toxin A & $11.72 \pm 2.58$ & \\
\cline { 2 - 3 } & GON,SON blokaj & $11.00 \pm 2.62$ & 0.462 \\
\hline T1 & Botilinum toxin A & $5.83 \pm 2.12$ & \multirow{2}{*}{0.747} \\
\cline { 2 - 3 } & GON,SON blokaj & $6.21 \pm 2.80$ & \\
\hline T6 & Botilinum toxin A & $4.22 \pm 1.43$ & \multirow{2}{*}{0.046} \\
\cline { 2 - 3 } & GON,SON blokaj & $5.89 \pm 2.60$ & \\
\hline T12 & Botilinum toxin A & $3.38 \pm 1.78$ & \multirow{2}{*}{0.005} \\
\cline { 2 - 3 } & GON,SON blokaj & $5.63 \pm 2.58$ & \\
\hline
\end{tabular}

who received botulinum toxin injection. No serious adverse effects were observed in either group. The VAS pain scores and frequency of attacks at pre-treatment, 1, 6, and 12 months after treatment were compared between the groups. No statistically significant difference was determined between the groups in respect of the pre-treatment VAS scores and frequency of attacks $(\mathrm{p}=0.310)$, in the 1-month values $(\mathrm{p}=0.468, \mathrm{p}=0.657)$, or the 6 -month values $(\mathrm{p}=0.400, \mathrm{p}=1.0)$. At 12 months, there was no significant difference between the groups in respect of the VAS scores $(p=0.850, p=1.0)$ and the frequency of attacks was determined to be statistically significantly lower in the botolinum toxin injection group $(\mathrm{p}=0.005)$.

\section{4 | DISCUSSION}

The results of this study showed that both GON and SON blockade and long-term application of BTX-A treatment were highly effective in the treatment of chronic migraine and both treatment methods had a similar level of effectiveness.

In the PREEMPT 1 and 2 studies of 1384 patients, a 24-week, double blind, parellel- group placebocontrolled phase was followed by a 32-week open label phase. The pooled analysis of the results showed that BTX-A treatment significantly reduced the frequency of headache days when compared to the placebo. In the double-blind group, there was a reduction of more than $50 \%$ in the number of headaches / days experienced by the patients, while the patients in the open label study group experienced a reduction of more than $60 \%$. The PREEMPT results showed a significant reduction in many of the patients' symptoms (7). Another study evaluated the results of 254 chronic migraine analyses in a prospective post-marketing data analysis, which showed that BTX-A application was effective in reducing headache and migraine days up to at least $50 \%$, simultaneously increasing the number of headache-free days (8).

A retrospective study by Guerzoni et al. reported a $67 \%$ reduction in acute drug intake and a $34 \%$ reduction in headache days (9). A Spanish study of 115 patients reported that chronic migraine became episodic migraine and the rate of response to treatment was $68.7 \%$ (10).

In a comparative review study of 4031 chronic migraine patients conducted with a placebo group, a significant reduction in monthly headache episodes was determined following the injection of botulinum toxin compared to the placebo. However, no change was shown in episodic migraine (11).

In the same review, it was found that BTX-A and placebo application did not significantly differ concerning the outcome of a $50 \%$ reduction in headache episodes per month for migraine or episodic migraine. In the same study, it was demonstrated that BTX-A could improve the impact of chronic migraine after 16 weeks of therapy, but this effect was not seen in episodic migraine (11). The side-effects reported in the review were myalgia, musculoskeletal stiffness, neck pain, paresthesia, blepharoptosis and neck weakness (11). 


\section{CURRENT MEDICAL RESEARCH AND OPINION}

Great occipital nerve blockade is the blockade most often applied in most migraine cases. In one study, large occipital nerve blockade was performed for chronic migraine, tension-type headache and cervicogenic headache, and a significant reduction in pain intensity was observed in patients with chronic migraine. (12).

In a randomized, double-blind placebo-controlled study conducted by Inan et al., a significant reduction in headache days and severity (VAS) was shown in patients with chronic migraine compared to the placebo group in treatment with large occipital nerve blockade for chronic migraine treatment. (13)

In a placebo-controlled study of patients with chronic migraine, Ozer et al. applied greater occipital nerve and supra orbital nerve blockade. There was a significant decrease in headache and VAS scores at the end of 3 months (14). In the treatment applied with local analgesics, no serious side-effects were observed except dizziness and injection site bleeding. $(14,15)$.

Gul et al., reported that recurrent GON blockade significantly decreased VAS and headache episodes in the 2 nd and 3rd months (15).

In a review by Inan et al, it was reported that the most commonly used blockade was to the large occipital nerve and bilateral blockade was not required due to diffusion. Repeated blockades were therefore recommended in migraine cases (13).

In an open label uncontrolled study, Miller S. et al reported a $69 \%$ response rate to treatment at 2 weeks after GON blockade in chronic migraine (16).

One of the disadvantages of botox application in the treatment of chronic migraine is the short duration of the effectiveness. Therefore, it has been stated that treatment is effective when the injections are repeated every 3 months. In a study of a 4-year followup of chronic migraine treatment, the wear-off phenomenon was encountered in $44 \%$ of the patients. The development of the wearing-off phenomenon leads to early discontinuation of treatment and causes patients to use more drugs than necessary (17).

In the light of the above-mentioned literature, peripheral nerve blockade with BTX-A and local anesthetics can be seen to be quite effective and is one of the treatment methods that can be used in the treatment of chronic migraine. Together with the relatively high cost, the development of antibodies and wearing-off phenomena make BTX treatment more disadvantageous. The use of local analgesics is much cheaper and there are fewer side-effects.

That the follow-up period of this study was longer than in previous research can be considered a strong aspect of the study.

\section{Limitations of the Study:}

Limitations of the study were primarily the low number of patients, the lack of healthy control subjects, and that the study was not blinded.

\section{5 | CONCLUSION:}

The results of this study have shown that both treatment modalities are highly effective and that the long-lasting blockade is also very effective. In terms of cost effectiveness and side-effects, local blockade could be considered more advantageous.

\section{REFERENCES}

1. Shen L, Wang. Impact of the botulinum-A toxin on prevention of adult migraine disorders. J Integr Neurosci. 2020;19(1):201-208.

2. Vos T, Flaxman AD, Naghavi M, Lozano. Years lived with disability (YLDs) for 1160 sequelae of 289 diseases and injuries 1990-2010: a systematic analysis for the Global Burden of Disease Study. Lancet. 2010;p. 380-380.

3. Dodick DW, Turkel CC, DeGryse RE, Aurora SK, Silberstein SD, Lipton RB, et al. OnabotulinumtoxinA for Treatment of Chronic Migraine: Pooled Results From the Double-Blind, Randomized, Placebo-Controlled Phases of the PREEMPT Clinical Program. Headache: The Journal of Head and Face Pain. 2010;50(6):921936. Available from: https://dx.doi.org/10.1111/ j.1526-4610.2010.01678.x. doi:10.1111/j.15264610.2010.01678.x. 
4. Gul HL, Ozon AO, Karadas O, Koc G, Inan LE. The efficacy of greater occipital nerve blockade in chronic migraine: A placebocontrolled study. Acta Neurologica Scandinavica. 2017;136(2):138-144. Available from: https://dx.doi.org/10.1111/ane.12716. doi:10.11 11/ane.12716.

5. Khalil M, Zafar H, Ahmed F. EHMTI-0223. Botox in the prevention of chronic migraine; 18months follow up outcome in 67 patients. The Journal of Headache and Pain. 2014;15(S1):11. Available from: https://dx.doi.org/10.1186/ 1129-2377-15-s1-g1. doi:10.1186/1129-2377-1 5-s1-g1.

6. Martinelli D, Arceri S, Tronconi L, Tassorelli C. Chronic migraine and Botulinum Toxin Type A: Where do paths cross? Toxicon. 2020;178:6976. Available from: https://dx.doi.org/10.1016/ j.toxicon.2020.02.017. doi:10.1016/j.toxicon.20 20.02.017.

7. Aicua-Rapun I, Martínez-Velasco E, Rojo A, Hernando A, Ruiz M, Carreres A, et al. Reallife data in 115 chronic migraine patients treated with Onabotulinumtoxin A during more than one year. The Journal of Headache and Pain. 2016;17(1):112-112. Available from: https://dx. doi.org/10.1186/s10194-016-0702-1. doi:10.11 86/s10194-016-0702-1.

8. Khan FA, Mohammed AE, Poongkunran M, Chimakurthy A, Pepper M. Wearing Off Effect of OnabotulinumtoxinA Near the End of Treatment Cycle for Chronic Migraine: A 4Year Clinical Experience. Headache: The Journal of Head and Face Pain. 2020;60(2):430 440. Available from: https://dx.doi.org/10.1111/ head.13713. doi:10.1111/head.13713.

9. Guerzoni S., Pellesi L., Baraldi C. Et al. Increased efficacy of regularly repeated cycles with OnabotulinumtoxinA in $\mathrm{MOH}$ patients beyond the first year of treatment, J Headache Pain. 2016; 17: 48.; 2019.

10. Özer D, Bölük C, Börü ÜT, Altun D, Taşdemir M, Toksoy CK. Greater occipital and supraor- bital nerve blockade for the preventive treatment of migraine: a single-blind, randomized, placebo-controlled study. Current Medical Research and Opinion. 2019;35(5):909915. Available from: https://dx.doi.org/10.1080/ 03007995.2018.1532403. doi:10.1080/0300799 5.2018.1532403.

11. Özer D, Bölük C, Börü ÜT, Altun D, Taşdemir M, Toksoy CK. Greater occipital and supraorbital nerve blockade for the preventive treatment of migraine: a single-blind, randomized, placebo-controlled study. Current Medical Research and Opinion. 2019;35(5):909915. Available from: https://dx.doi.org/10.1080/ 03007995.2018.1532403. doi:10.1080/0300799 5.2018 .1532403 .

12. Inan3 N. Greater occipital nerve block in migraine prophylaxis: Narrative review. Headache Society. 2019;2(0):1-13.

13. Vos T, Allen, C, Arora. Global, regional, and national incidence, prevalence, and years lived with disability for 310 diseases and injuries, 1990-2015: a systematic analysis for the Global Burden of Disease Study. Lancet. 2015;388:1545-1602.

14. Duygu Özer 1, Cem Bölük , Ülkü Türk Börü et al., Greater occipital and supraorbital nerve blockade for the preventive treatment of migraine: a single-blind, randomized, placebocontrolled study, Curr Med Res Opin. 2019 May;35(5):909-915.;.

15. Terzi T, Karakurum B, Üçler S, İnan LE, Tulunay C. Greater occipital nerve blockade in migraine, tension-type headache and cervicogenic headache. The Journal of Headache and Pain. 2002;3(3):137-141. Available from: https://dx. doi.org/10.1007/s101940200031. doi:10.1007/s 101940200031.

16. Sarah Miller, Susie Lagrata et al. Multiple cranial nerve blocks for the transitional treatment of chronic headaches Cephalalgia 0(0) 1-12 International Headache Society 2019; 2019. 
17. Guerzoni S, Pellesi L, Baraldi C, Pini LA. Increased efficacy of regularly repeated cycles with OnabotulinumtoxinA in $\mathrm{MOH}$ patients beyond the first year of treatment. The Journal of Headache and Pain. 2016;17(1):4848. Available from: https://dx.doi.org/10.1186/ s10194-016-0634-9. doi:10.1186/s10194-016-0 634-9.
How to cite this article: Bilgic A.B., Akpinar C.K., Boru U.T., Ramazanoglu L. Peripheral Nerve Blockade and Botox Treatment in Chronic Migraine: A Comparative Study. Journal of Current Medical Research and Opinion. 2021;878-885. https://doi.org/10.15520/jcmro.v4i03.410 